\title{
What prompts help-seeking for cancer 'alarm' symptoms? A primary care based survey
}

\author{
K L Whitaker ${ }^{\star}, 1, C$ Friedemann Smith ${ }^{2}$, K Winstanley ${ }^{2}$ and J Wardle ${ }^{2, *}$ \\ ${ }^{1}$ School of Health Sciences, University of Surrey, Guildford, Surrey GU2 7XH, UK and ${ }^{2}$ Health Behaviour Research Centre, \\ Department of Epidemiology and Public Health, University College London, London WC1E 6BT, UK
}

Background: Encouraging prompt help-seeking for cancer symptoms can help shorten the patient interval and improve timely diagnosis. We explored factors associated with help-seeking in a primary care sample reporting 'alarm' symptoms.

\begin{abstract}
Methods: A questionnaire was mailed to 9771 adults ( $\geqslant 50$ years of age and no cancer diagnosis) and 3766 (39\%) returned it. Our sample included 1732 adults reporting at least one cancer 'alarm' symptom; with a total of 2726 symptoms. Respondents completed questions relating to help-seeking, demographic and symptom characteristics (e.g., type, knowledge, concern, interference and attribution).
\end{abstract}

Results: Over a third of people who reported a cancer 'alarm' symptom in the past 3 months had not sought help from a doctor. An unexplained lump (odds ratio (OR) 2.46, 1.42-4.26) and persistent unexplained pain (OR 1.79, 1.19-2.69) were associated with increased likelihood of help-seeking. Symptom concern (OR 3.10, 2.19-4.39) and interference (OR 3.06, 2.15-4.36) were associated with an increased likelihood of seeking help independently of symptom type. People who were not working (OR 1.41, 1.09-1.83), were married/cohabiting rather than single (OR 1.38, 1.10-1.74) and were older (60-69 years) rather than younger (50-59 years; OR $1.33,1.02-1.75)$ were more likely to have sought help.

Conclusions: Our findings highlighted symptom type and symptom characteristics as key drivers of help-seeking. We also found that there may be specific demographic groups where encouraging help-seeking might be warranted.

More timely diagnosis of cancer is likely to result in positive patient outcomes, in terms of improved survival, earlier stage at diagnosis, improved quality of life and improved patient experience (Mendonca et al, 2015; Neal et al, 2015). The majority of cancer diagnoses are made following symptomatic presentation (Hamilton, 2009), suggesting that the decision to seek help for a potential symptom is an important focus of research. Facilitating prompt response to symptoms possibly indicative of cancer, and empowering patients in the process of seeking medical help is key to ongoing public health efforts to improve the earlier diagnosis of cancer (Cancer Research UK, 2015; Public Health England, 2015).

The decision to consult a doctor is based on a mix of social and psychological factors (Campbell and Roland, 1996; Scott et al, 2012). Previous community-based research has largely explored factors associated with help-seeking for cancer symptoms by asking people to estimate how likely they would be to seek help for 'imagined' symptoms using the Cancer Awareness Measure (CAM) (Robb et al, 2009; Quaife et al, 2014). These studies have shown that lower cancer awareness and higher perceived barriers (e.g., worry about wasting the doctor's time) are associated with longer anticipated delay. These correlates of help-seeking have also been consistently associated with sociodemographic characteristics: older, single people and those from lower socioeconomic groups recognise fewest 'alarm' symptoms and report more barriers (Niksic et al, 2015). However, by definition these studies cannot estimate the role of symptom experience on help-seeking because the symptoms are hypothetical.

Evidence from symptom studies in primary care suggests that although demographic differences in help-seeking emerge (e.g., women were more likely to consult than men), the characteristics of the symptom itself (e.g., severity and interference with daily life) have the biggest influence on help-seeking (Elliott et al, 2011, 2012).

*Correspondence: Dr KL Whitaker; E-mail: k.whitaker@surrey.ac.uk

Deseased.

Received 29 September 2015; revised 25 November 2015; accepted 30 November 2015; published online 21 January 2016

(c) 2016 Cancer Research UK. All rights reserved 0007-0920/16

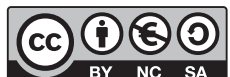


Nonetheless, generic symptom surveys in primary care may provide only limited information on how people respond to potential cancer symptoms, partly because the timeframe people report about is often short (e.g., 2 weeks) (McAteer et al, 2011).

More recently, a strand of research has started to explore people's real-life experience of cancer 'alarm' symptoms, without imposing the word 'cancer' (Whitaker et al, 2014). This strategy involves asking people about their general health with questions on cancer symptoms embedded among others. Using this approach, the prevalence of the 10 classic cancer 'alarm' symptoms from the CAM is extremely high ( $53 \%$ of people report at least one 'alarm' symptom in the past 3 months), and just over half of people reporting an 'alarm' symptom had seen a doctor (Whitaker et al, 2014). In qualitative interviews with a subset of people reporting alarm symptoms $(n=48)$, perceiving the symptom as serious was a main reason for help-seeking (Whitaker et al, 2015b). However, to date there has not been a quantitative exploration of factors associated with help-seeking in this context.

Another relatively unexplored issue is whether some symptoms are more likely to trigger help-seeking than others. Data from nearly 2000 cancer patients completing the Department of Health's Cancer Patient Experience Survey demonstrated that change in bladder or bowel habits and unexplained weight loss were associated with longer delay in presentation, while a lump was responded to more rapidly (Forbes et al, 2014). However, evidence from cancer patients only includes those who sought help and were subsequently diagnosed with cancer, and does not give us insight into those currently interpreting 'alarm' symptoms.

In the present study, we used data pooled from two large primary care based surveys (Whitaker et al, 2015c) to explore symptom-related correlates of help-seeking for 10 classic 'alarm' symptoms in the daily context. Following previous research, we hypothesised the following:

(a) Well-known red-flag symptoms such as an 'unexplained lump' would be associated with higher levels of help-seeking compared with other symptoms such as 'persistent change in bladder habits'.

(b) Symptoms that were considered concerning, interfering or associated with cancer would be associated with higher levels of help-seeking than those not considered concerning, interfering or associated with cancer.

(c) Certain demographic sub-groups (e.g., people not working) would be more likely to seek help for their symptoms.

\section{METHODS}

Sample. The study population has been described previously (Whitaker et al, 2015c). Questionnaires were sent to 9771 men and women aged $\geqslant 50$ years, registered at seven GP practices across London, the South East and the North West of England in April 2012 and October 2013. All patients $\geqslant 50$ years without a cancer diagnosis and deemed suitable by the doctor (e.g., did not have mental illness, terminal illness or learning disability) were eligible. Non-responders were sent a reminder after 2 weeks. The study materials and protocol were approved by NHS London Bridge Research Ethics Committee (Reference: 11/LO/1970) and all patients gave informed consent.

The questionnaire. The self-completion questionnaire asked about experience of 10 cancer 'alarm' symptoms over the past 3 months. The symptoms were from the CAM (Stubbings et al, 2009) and included: persistent cough or hoarseness; persistent change in bowel habits; persistent unexplained pain; persistent change in bladder habits; unexplained lump; a change in the appearance of a mole; a sore that does not heal; unexplained bleeding; unexplained weight loss; or persistent difficulty swallowing.

If participants responded 'yes' to having experienced any symptom they were asked whether they had been concerned that the symptom might be serious, and how much it had interfered with their daily life, with responses on a 5-point Likert scale from 'not at all' to 'extremely'. Ratings of 4 or 5 were taken to indicate higher concern or higher interference. Participants were asked an open-response item 'What do you think caused it' from which we coded mention of cancer. Participants were also asked if they had seen or spoken to a GP about the symptom (yes/no).

Knowledge of cancer symptoms was assessed with the CAM (Stubbings et al, 2009), modified so that respondents were asked to tick whether each of the listed symptoms could be indicative of three illnesses (cancer, heart disease and asthma). This was designed to mask the cancer context. For each symptom participants scored 1 if they correctly identified it as a symptom of cancer, and 0 if they did not.

Questions on marital status, ethnicity, education and employment were included and practices gave information on age and sex of all those approached for the survey.

Statistical analysis. Data were analysed using SPSS 22.0 (Armonk, NY, USA). Descriptive statistics were completed for demographic variables, symptom prevalence and symptom characteristics. Details of the coding and analysis of mentions of cancer have been published elsewhere (Whitaker et al, 2015c).

We restructured the data set so that every symptom reported was included in the analysis. For all analyses, we used complex samples with a two-stage cluster sampling design. In this design, individual symptoms were grouped into clusters of participants reporting them; at the first sampling stage, clusters (participants) were selected and at the second stage an element (symptom) from each cluster was randomly selected. This was done to ensure that for participants reporting multiple symptoms, the corresponding symptom-specific measures (e.g., concern and knowledge), and help-seeking behaviour were used in the analysis, as different symptoms may have elicited different responses.

We also weighted the analyses by number of symptoms reported. For example, if a participant reported five symptoms, the weighting for each symptom was $1 / 5$ or 0.2 . Univariate logistic regression was used to examine individual relationships between symptom characteristics (including symptom type, concern, interference and mention of cancer), cancer symptom 'aware' (yes/no), demographic variables and help-seeking. Finally, we ran a multivariate logistic regression model to explore the independent contribution of potential factors.

\section{RESULTS}

Response. The response to the survey, including non-responder analysis has been reported previously (Whitaker et al, 2015c). Men and the youngest age group (50-59-year-olds) were less likely to respond to the survey. From 9771 people invited to participate, 3766 (38.5\%) sent back a questionnaire, but 6005 (61.5\%) did not reply after one reminder. Ten people did not complete the symptom questions resulting in a final sample of 3756 . Of the 3756 with full data, $1732(46 \%)$ reported at least one 'alarm' symptom and were included in the current analysis. The number of symptoms reported ranged from 1 to $10 \quad($ mean $=1.73$, s.d. =1.17), with a total of 2998 'alarm' symptoms reported. Because of missing help-seeking data for 272 symptoms, the final data set consisted of 2726 symptoms for logistic regression analyses. 
Demographic characteristics for the sample reporting symptoms are presented in Table $1(n=1732)$ and compared with the total sample $(n=3756)$. The average age of the sample reporting symptoms was 65 years (range: 50-102 years old). Respondents were $56 \%$ women $(n=962), 87 \%$ white $(n=1485), 57 \%$ married $(n=975), 39 \%$ with a university degree $(n=648)$ and $39 \%$ working $(n=660)$. This demographic profile is very similar to the profile of the total sample (Whitaker et al, 2015c). It is also comparable to the demographic profile of over 50-year olds in England, according to the Office for National Statistics Data (ONS, 2011a): 53\% women (ONS, 2011f); $93 \%$ white (ONS, 2011d); 50\% married (ONS, 2011e); 23\% with a university degree (ONS, 2011c); and $40 \%$ working (ONS, 2011b).

Across symptoms, 67\% (1101 out of 1645) of people had sought help for at least one symptom, although this varied at the symptom level (Table 2). The frequencies of each of the cancer alarm symptoms have been published previously (Whitaker et al, 2015c). The most commonly reported symptoms were persistent cough or hoarseness (17\%) and persistent change in bowel habits (13\%). The least commonly reported symptoms were persistent difficulty swallowing and unexplained bleeding (both 3\%).

What symptoms led to help-seeking? In adjusted analyses (Table 3), unexplained lump or persistent unexplained pain were associated with the highest levels of help-seeking (72\% and $70 \%$ of participants, respectively, had seen a doctor). Persistent cough or hoarseness, change in bladder habits and unexplained bleeding had the lowest levels of help-seeking (53-54\% of people had seen a doctor for these symptoms). In multivariate logistic regression analyses, controlling for demographic factors and symptom characteristics (including concern and level of interference), people were significantly more likely to seek help for an unexplained lump (odds ratio (OR) 2.46, 1.42-4.26) and persistent unexplained pain (OR 1.79, 1.19-2.69) than persistent cough or hoarseness, persistent change in bladder habits or unexplained bleeding (Table 3). Although we used change in bladder habits as the reference category, the results were the same when we used unexplained bleeding or persistent cough or hoarseness as the reference category.

What was the role of specific symptom characteristics? Symptoms that were concerning (OR 3.10, 2.19-4.39) or interfering (OR 3.06, 2.15-4.36) were associated with a higher chance of help-seeking in

\section{Table 1. Demographic characteristics \% (n)}

\begin{tabular}{|c|c|c|}
\hline & $\begin{array}{l}\text { Symptom sample } \\
\quad(n=1732)\end{array}$ & $\begin{array}{c}\text { Total sample } \\
(n=3756)\end{array}$ \\
\hline \multicolumn{3}{|l|}{ Education } \\
\hline University & $38.5(648)$ & $38.7(1422)$ \\
\hline Below university & $61.5(1036)$ & $61.3(2250)$ \\
\hline \multicolumn{3}{|l|}{ Sex } \\
\hline Men & $43.4(751)$ & $46.3(1723)$ \\
\hline Women & 55.5 (962) & 53.7 (1996) \\
\hline \multicolumn{3}{|l|}{ Age, years } \\
\hline $50-59$ & $34.6(565)$ & $34.6(1273)$ \\
\hline $60-69$ & $35.7(583)$ & $37.3(1374)$ \\
\hline $70+$ & $29.8(487)$ & $28.0(1030)$ \\
\hline \multicolumn{3}{|l|}{ Employment } \\
\hline Working & $38.5(660)$ & 42.7 (1587) \\
\hline Not working & $61.5(1053)$ & $57.3(2129)$ \\
\hline \multicolumn{3}{|l|}{ Ethnicity } \\
\hline White & $86.7(1485)$ & $88.5(3293)$ \\
\hline Other & $13.3(227)$ & $11.5(428)$ \\
\hline \multicolumn{3}{|l|}{ Marital status } \\
\hline Married/cohabiting & $57.0(975)$ & $62.3(2316)$ \\
\hline Not married/cohabiting & $43.0(736)$ & $37.7(1400)$ \\
\hline
\end{tabular}

both univariate and multivariate analysis. Mentioning cancer as a possible cause was also associated with higher odds of help-seeking (OR 2.03, 1.12-3.70), although this relationship was not significant in multivariate analyses (OR 1.79, 0.87-3.70). Finally, knowing that a symptom could be a warning sign of cancer (i.e., endorsing it on the CAM) was not associated with help-seeking in either analysis $(P>0.05)$.

Who was most likely to seek help? Controlling for symptom type, symptom characteristics and other demographic factors, people not working (OR 1.41, 1.09-1.83), aged 60-69 years vs 50-59 years (OR 1.33, 1.02-1.75) and married/cohabiting (OR 1.38, 1.10-1.74) were more likely to seek help across symptoms. Education (1.03, 0.82-1.30), sex (OR 1.16, 0.92-1.45) and ethnicity (OR $0.81,0.57-1.15$ ) were not associated with helpseeking in multivariate analysis.

\section{DISCUSSION}

Over a third of adults ( $\geqslant 50$ years of age) surveyed through primary care had experienced cancer 'alarm' symptoms that they had not sought help for. Symptom type influenced help-seeking with persistent cough or hoarseness, persistent change in bladder habits and unexplained bleeding associated with lower odds of help-seeking and unexplained lump and persistent unexplained pain associated with the highest odds of help-seeking.

These findings support a recent survey quantifying risk factors for delay in cancer patients, where urinary symptoms and rectal bleeding were associated with greater delay, while unexplained lump was generally dealt with promptly (Forbes et al, 2014). One suggestion is that the difference lies in symptom intensity/onset, with an unexplained lump and persistent unexplained pain more likely to appear rapidly and thus less likely to be associated with normal variation in bodily sensations (Forbes et al, 2014). Normalising is consistently mentioned in the literature as a risk factor for delay (Smith et al, 2005; Macleod et al, 2009). Notably, the symptoms in our study associated with the lowest rates of helpseeking also have plausible alternative explanations, particularly in this older age group (e.g., haemorrhoids for rectal bleeding and ageing for change in bladder habits) (Mor et al, 1990).

Further evidence for the importance of the nature of the symptom was found, with symptoms rated as concerning and interfering associated with higher odds of help-seeking, independently of symptom type. This echoes findings from the broader symptom literature, where symptom severity and interference alongside causal attributions were most consistent predictors of help-seeking (Stoller and Forster, 1994).

We found that attributing a symptom to cancer was not related to help-seeking in multivariate analysis. However, very few people (3.6\%) considered cancer as a possible cause, which makes it difficult to observe significant differences. Nonetheless, others have reported similar findings; a delay of 3 or more months was equally likely in people who attributed their symptoms to cancer as in those who did not (Mor et al, 1990). In another study with colorectal cancer patients, people experiencing rectal bleeding were more likely to have considered cancer as a possible cause, but rectal bleeding was associated with prolonged patient intervals (Pedersen et al, 2013). Among those who apparently recognised the implications of their symptom, some may be 'in denial', or the fear of a cancer diagnosis may lead to the undesirable response of avoiding help-seeking (Whitaker et al, 2015a).

Although very few people spontaneously mentioned cancer as a possible cause of their symptom, a significant proportion endorsed the symptom they reported as a warning sign of cancer (ranging from $51 \%$ for persistent cough or hoarseness to $90 \%$ for change in the appearance of a mole) when they completed the CAM. 
Table 2. Symptom prevalence and symptom characteristics for all symptoms $(\boldsymbol{n}=\mathbf{2 9 9 8 )}$

\begin{tabular}{|c|c|c|c|c|c|c|c|c|c|c|}
\hline$\%(n)$ & $\begin{array}{l}\text { Cough or } \\
\text { hoarseness }\end{array}$ & $\begin{array}{c}\text { Change } \\
\text { in bowel } \\
\text { habits }\end{array}$ & $\begin{array}{l}\text { Unexplained } \\
\text { pain }\end{array}$ & $\begin{array}{c}\text { Change in } \\
\text { bladder } \\
\text { habits }\end{array}$ & $\begin{array}{l}\text { Change } \\
\text { in mole }\end{array}$ & $\begin{array}{l}\text { Unexplained } \\
\text { lump }\end{array}$ & $\begin{array}{c}\text { Sore that } \\
\text { does not } \\
\text { heal }\end{array}$ & $\begin{array}{l}\text { Unexplained } \\
\text { weight loss }\end{array}$ & $\begin{array}{l}\text { Difficulty } \\
\text { swallowing }\end{array}$ & $\begin{array}{c}\text { Unexplained } \\
\text { bleeding }\end{array}$ \\
\hline $\begin{array}{l}\text { Symptom } \\
\text { prevalence }\end{array}$ & 16.9 (629) & $12.9(483)$ & $12.8(476)$ & $11.1(413)$ & $7.3(273)$ & $5.5(205)$ & $4.0(148)$ & $3.8(143)$ & $3.2(120)$ & $2.9(108)$ \\
\hline $\begin{array}{l}\text { Attributed } \\
\text { symptom to } \\
\text { cancer }\end{array}$ & $1.5(8)$ & $3.0(11)$ & $1.4(5)$ & $0.7(2)$ & 10.7 (19) & $8.8(13)$ & $3.5(4)$ & $0.9(1)$ & $4.6(4)$ & $4.7(4)$ \\
\hline $\begin{array}{l}\text { Interferes with } \\
\text { daily life }\end{array}$ & $20.0(122)$ & 25.7 (118) & 40.2 (182) & $25.8(101)$ & $4.6(12)$ & $12.2(24)$ & $26.8(38)$ & $16.7(22)$ & $18.0(20)$ & $15.8(16)$ \\
\hline $\begin{array}{l}\text { Symptom } \\
\text { aware }\end{array}$ & $50.8(316)$ & 78.4 (377) & $60.6(288)$ & $68.7(281)$ & $90.4(246)$ & 83.8 (171) & $61.9(91)$ & 64.5 (91) & $54.6(65)$ & $84(79.2)$ \\
\hline $\begin{array}{l}\text { Contacted GP } \\
\text { about the } \\
\text { symptom }\end{array}$ & $53.5(317)$ & $57.9(246)$ & 70.7 (311) & $56.1(371)$ & $54.0(135)$ & 72.0 (139) & $62.6(82)$ & $56.6(73)$ & $61.2(63)$ & $57.9(55)$ \\
\hline
\end{tabular}

However, contrary to previous research being 'symptom aware' was not associated with being more likely to seek help. Previous research has observed a relationship between cancer awareness and anticipated help-seeking for hypothetical symptoms (Robb et al, 2009; Quaife et al, 2014). This discrepancy may reflect differences between what people say they would do 'in theory' and how they behave in practice (Sheeran, 2002). Raising awareness of cancer 'alarm' symptoms to enhance prompt help-seeking should thus be considered one strand of a complex set of influences on helpseeking behaviour.

As with previous research, some demographic sub-groups were more likely to seek help than others, particularly those not working, aged 60-69 years, and who were married or living with someone. Identifying sub-groups who are more or less likely to seek help may be useful for informing social marketing campaigns (Niksic et al, 2015).

Contrary to previous research (Forbes et al, 2014), we did not find evidence that lower education was associated with being less likely to seek help, although this may reflect the use of help-seeking (yes/no) as an outcome, rather than measuring patient intervals. Epidemiological evidence for inequalities in stage at diagnosis across common cancers is striking (Lyratzopoulos et al, 2013), with a clear role for differences in how people interpret and respond to symptoms (Lyratzopoulos and Abel, 2013). Our previous research demonstrated that lower education was associated with lower likelihood of cancer suspicion in people experiencing cancer 'alarm' symptoms (Whitaker et al, 2015c). One possibility is that socioeconomic differences are more likely to be observed in how people interpret, rather than respond to symptoms (i.e., once people acknowledge the possibility of cancer, there may be more equity in how they respond). This hypothesis requires further consideration.

There has been a major shift in how symptom research has been conducted since the establishment of the Aarhus statement (Weller et al, 2012), with improved clarity in definitions and greater appreciation of potential biases influencing measurement of helpseeking (Scott et al, 2012). By pooling data across two large surveys, we were able to stratify our help-seeking analyses by presenting symptom, rather than cancer type, providing a more accurate reflection of influences on help-seeking (Dobson et al, 2014). A next step for research would be to explore associations with specific time intervals and to focus on specific cancers, where the patient interval has been implicated (Lyratzopoulos and Abel, 2013; Dobson et al, 2014).

In the past, there was concern that asking people about 'alarm' symptoms without following them up would be unethical
(Scott and Walter, 2010). However, only asking people about the experience of 'alarm' symptoms once they are definitively linked with cancer is associated with retrospective bias, and asking about hypothetical symptoms may provide limited information on how people actually behave. The low predictive value of the 'alarm' symptoms we included (Jones et al, 2007; Hamilton, 2009), in combination with a general recommendation to contact the GP if symptoms persist, meant we have been able to conduct surveys comparable to generic symptom surveys to explore how people respond to 'alarm' symptoms in the daily context (Elliott et al, $2011,2012)$. Although for the majority of people their symptom probably indicates a benign condition, there is a possibility that the symptom is a sign of cancer, and making the decision to seek help earlier is likely to result in more positive patient outcomes (Mendonca et al, 2015; Neal et al, 2015).

Our study asked about symptoms in the past 3 months and we do not know the exact length of the patient interval, or if the symptom was new or recurrent. On one hand, using a dichotomous variable for help-seeking (yes/no) is advantageous because it did not require people to recall dates, which is known to be difficult (Pedersen et al, 2013), but is a limitation when comparing our findings to previous research. There is also growing evidence that the experience of 'false alarms' (i.e., going to a GP with a symptom and being given a benign diagnosis) impacts on subsequent help-seeking (Renzi et al, 2015) and it may be important for future research to distinguish between new or recurrent symptoms.

Another weakness of the study is that we do not have data on the symptom experience of non-responders, a problem inherent in epidemiological research (Galea and Tracy, 2007). However, our sample was generally representative of people aged 50 years older living in England, according to sex, marital status, employment and ethnicity (ONS, 2011a). As might be expected, there were more people with a degree in our study (39\%) than in the general population $(23 \%)$, a finding that reflects that people from more deprived backgrounds were less likely to return the survey (Whitaker et al, 2014). We also had very low numbers of people from non-white ethnic groups, which means we cannot generalise to people of non-white origin. We may need to find alternative approaches for exploring symptom experiences in hard-to-reach or minority groups.

In conclusion, the results of the present study showed that significant numbers of men and women experience cancer 'alarm' symptoms and do not seek help. Persistent cough or hoarseness, persistent change in bladder habits and unexplained bleeding were associated with being less likely to seek help compared with an 
Table 3. Associations of demographic and symptom characteristics with help-seeking for possible cancer symptoms

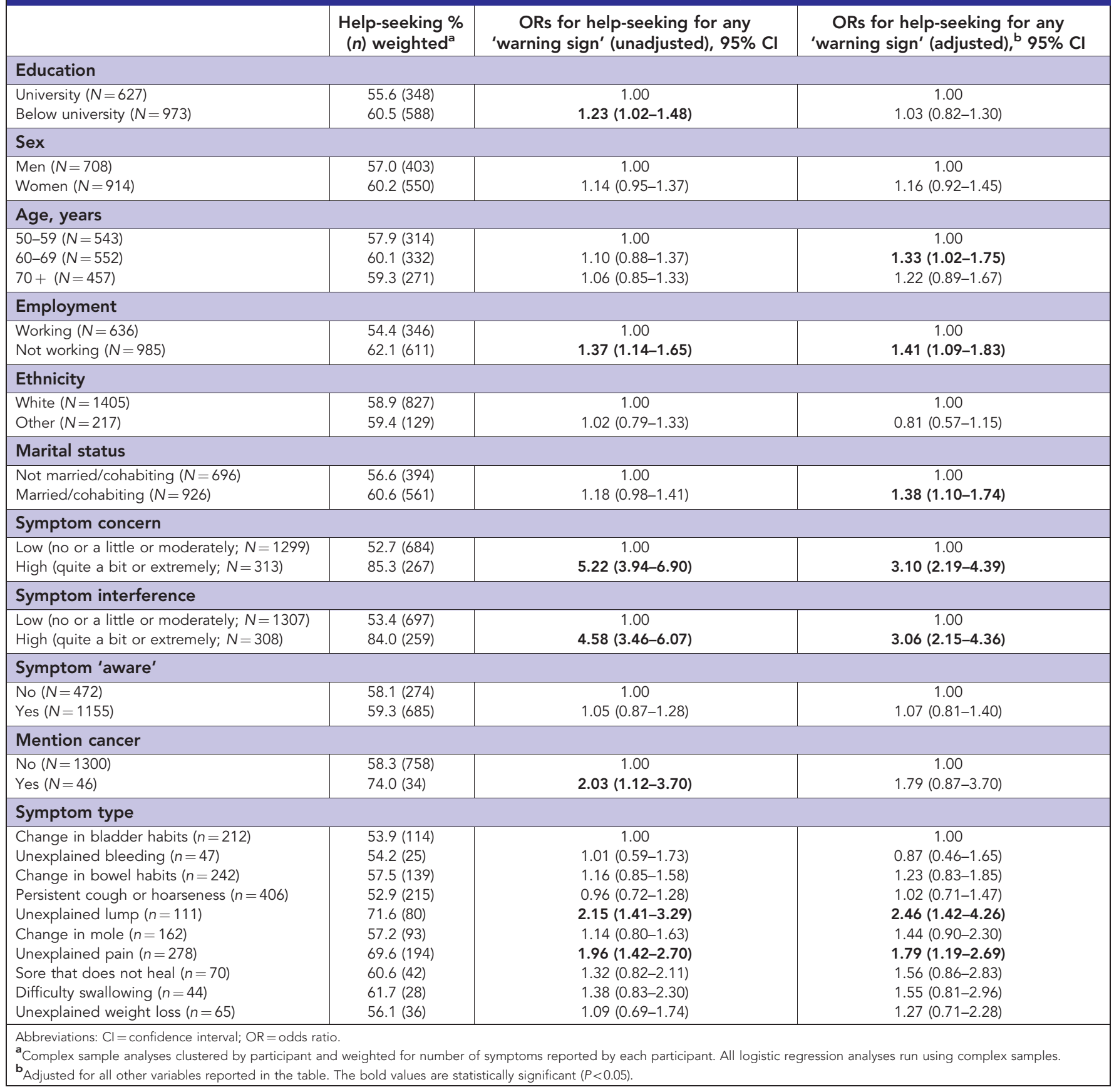

unexplained lump or persistent unexplained pain. Considering cancer as a possible cause or cancer knowledge (measured by the CAM) were not associated with being more likely to seek help, while symptoms that were concerning and interfering were associated with help-seeking. We also found that people who were working, were not married/cohabiting or were younger (50-59 years) rather than older (60-69 years) were less likely to have sought help.

Public health campaigns aimed at improving awareness of cancer 'alarm' symptoms in order to achieve earlier diagnosis may need to consider broader influences on help-seeking behaviour.

\section{ACKNOWLEDGEMENTS}

In memory of Professor Jane Wardle (1950-2015). These analyses were carried out with funding from the Department of Health Policy
Research Unit in Cancer Awareness, Screening and Early Diagnosis awarded to JW and a Cancer Research UK Post-doctoral fellowship grant awarded to KLW (C33872/A13216). The Policy Research Unit in Cancer Awareness, Screening and Early Diagnosis receives funding for a research programme from the Department of Health Policy Research Programme. It is a collaboration between researchers from seven institutions (Queen Mary University of London, University College London, King's College London, London School of Hygiene and Tropical Medicine, Hull York Medical School, Durham University and Peninsula Medical School). The views expressed are those of the authors and not necessarily those of the NHS or the Department of Health.

\section{CONFLICT OF INTEREST}

The authors declare no conflict of interest. 


\section{REFERENCES}

Campbell SM, Roland MO (1996) Why do people consult the doctor? Fam Pract 13(1): 75-83.

Cancer Research UK (2015) National Awareness and Early Diagnosis Initiative (NAEDI). Available at http://wwwcancerresearchukorg/healthprofessional/early-diagnosis-activities/national-awareness-and-earlydiagnosis-initiative-naedi (accessed on 18 May 2015).

Dobson CM, Russell AJ, Rubin GP (2014) Patient delay in cancer diagnosis: what do we really mean and can we be more specific? BMC Health Serv Res 14: 387.

Elliott AM, McAteer A, Hannaford PC (2011) Revisiting the symptom iceberg in today's primary care: results from a UK population survey. BMC Fam Pract 12: 16.

Elliott AM, McAteer A, Hannaford PC (2012) Incongruous consultation behaviour: results from a UK-wide population survey. BMC Fam Pract 13: 21.

Forbes L, Warburton F, Richard MA, Ramirez A (2014) Risk factors for delay in symptomatic presentation: a survey of cancer patients. $\mathrm{Br}$ J Cancer 111(3): 581-588.

Galea S, Tracy M (2007) Participation rates in epidemiologic studies. Ann Epidemiol 17(9): 643-653.

Hamilton W (2009) The CAPER studies: five case-control studies aimed at identifying and quantifying the risk of cancer in symptomatic primary care patients. Br J Cancer 101: S80-S86.

Jones R, Latinovic R, Charlton J, Gulliford MC (2007) Alarm symptoms in early diagnosis of cancer in primary care: cohort study using General Practice Research Database. BMJ 334(7602): 1040.

Lyratzopoulos G, Abel G (2013) Earlier diagnosis of breast cancer: focusing on symptomatic women. Nat Rev Clin Oncol 10: 544.

Lyratzopoulos G, Abel G, Brown C, Rous B, Vernon S, Roland M, Greenberg D (2013) Socio-demographic inequalities in stage of cancer diagnosis: evidence from patients with female breast, lung, colon, rectal, prostate, renal, bladder, melanoma, ovarian and endometrial cancer. Ann Oncol 24(3): 843-850.

Macleod U, Mitchell ED, Burgess C, Macdonald S, Ramirez AJ (2009) Risk factors for delayed presentation and referral of symptomatic cancer: evidence for common cancers. Br J Cancer 101: S92-S101.

McAteer A, Elliott AM, Hannaford PC (2011) Ascertaining the size of the symptom iceberg in a UK-wide community-based survey. $\mathrm{Br} \mathrm{J}$ Gen Pract 61(582): 12-17.

Mendonca SC, Abel GA, Saunders CL, Wardle J, Lyratzopoulos G (2015) Pre-referral general practitioner consultations and subsequent experience of cancer care: evidence from the English Cancer Patient Experience Survey. Eur J Cancer Care (Engl); e-pub ahead of print 30 July 2015; doi:10.1111/ecc.12353.

Mor V, Masterson-Allen S, Goldberg R, Guadagnoli E, Wool M (1990) Pre-diagnostic symptom recognition and help seeking among cancer patients. J Community Health 15(4): 253-266.

Neal RD, Tharmanathan P, France B, Din NU, Cotton S, Fallon-Ferguson J, Hamilton W, Hendry A, Hendry M, Lewis R, Macleod U, Mitchell ED, Pickett M, Rai T, Shaw K, Stuart N, Torring ML, Wilkinson C, Williams B, Williams N, Emery J (2015) Is increased time to diagnosis and treatment in symptomatic cancer associated with poorer outcomes? Systematic review. $\mathrm{Br} J$ Cancer 112: S92-S107.

Niksic M, Rachet B, Warburton FG, Wardle J, Ramirez AJ, Forbes LJL (2015) Cancer symptom awareness and barriers to symptomatic presentation in England- are we clear on cancer? Br J Cancer 113(3): 533-542.

ONS (2011a) Census 2011. Available at: http://www.ons.gov.uk/ons/guidemethod/census/2011/index.html (accessed on 11 December 2015).

ONS (2011b) Economic activity by age. Available at: http://www.nomisweb. co.uk/census/2011/lc6107ew (accessed on 28 September 2015).
ONS (2011c) Education by age. Available at: http://www.nomisweb.co.uk/ census/2011/dc5203ew (accessed on 28 September 2015).

ONS (2011d) Ethnic group by age. Available at: http://www.nomisweb.co.uk/ census/2011/lc2109ewls (accessed on 28 September 2015).

ONS (2011e) Marital status by age. Available at: http://www.nomisweb.co.uk/ census/2011/DC1101EW/view/2092957699?rows=c_age\&cols=c_marstat (accessed on 28 September 2015).

ONS (2011f) Sex by age. Available at: http://www.nomisweb.co.uk/census/ 2011/lc1117ew (accessed on 28 September 2015).

Pedersen AF, Hansen RP, Vedsted P (2013) Patient delay in colorectal cancer patients: associations with rectal bleeding and thoughts about cancer. PLoS One 8(7): e69700.

Public Health England (2015) Be clear on cancer. Available at http://campaignsdh. gov.uk/category/beclearoncancer/ (accessed on 23 February 2015).

Quaife SL, Forbes LJL, Ramirez AJ, Brain KE, Donnelly C, Simon AE, Wardle J (2014) Recognition of cancer warning signs and anticipated delay in helpseeking in a population sample of adults in the UK. Br J Cancer 110(1): 12-18.

Renzi C, Whitaker KL, Wardle J (2015) Over-reassurance and under-support after a 'false alarm': a review of the impact on subsequent cancer symptom attribution and help-seeking. BMJ Open 5: e007002.

Robb K, Stubbings S, Ramirez A, Macleod U, Austoker J, Waller J (2009) Public awareness of cancer in Britain: a population-based survey of adults. Br J Cancer 101(Suppl 2): S18-S23.

Scott S, Walter F (2010) Studying help-seeking for symptoms: the challenges of methods and models. Soc Personal Psychol Compass 4/8: 531-547.

Scott SE, Walter FM, Webster A, Sutton S, Emery J (2012) The model of pathways to treatment: conceptualization and integration with existing theory. Br J Health Psychol 18: 45-65.

Sheeran P (2002) Intention-behavior relations: a conceptual and empirical review. Eur Rev Soc Psychol 12(1): 1-36.

Smith LK, Pope C, Botha JL (2005) Patients' help-seeking experiences and delay in cancer presentation: a qualitative synthesis. Lancet 366(9488): 825-831.

Stoller EP, Forster LE (1994) The impact of symptom interpretation on physician utilization. J Aging Health 6(4): 507-534.

Stubbings S, Robb K, Waller J, Ramirez A, Austoker J, Macleod U (2009) Development of a measurement tool to assess public awareness of cancer. Br J Cancer 101: S13-S17.

Weller D, Vedsted P, Rubin G, Walter F, Emery J, Scott S, Campbell C, Andersen R, Hamilton W, Olesen F, Rose P, Nafees S, van Rijswijk E, Hiom S, Muth C, Beyer M, Neal R (2012) The Aarhus statement: improving design and reporting of studies on early cancer diagnosis. $\mathrm{Br} \mathrm{J}$ Cancer 106(7): 1262-1267.

Whitaker KL, Cromme S, Winstanley K, Renzi C, Wardle J (2015a) Emotional responses to the experience of cancer 'alarm' symptoms. Psychooncology; e-pub ahead of print 11 September 2015; doi:10.1002/pon.3964.

Whitaker KL, Macleod U, Winstanley K, Scott S, Wardle J (2015b) Helpseeking for cancer 'alarm' symptoms: a qualitative interview study. $\mathrm{Br} J$ Gen Pract 65(631): e96.

Whitaker KL, Scott SE, Winstanley K, Macleod U, Wardle J (2014) Attributions of cancer 'alarm' symptoms in a community sample. PLoS One 9(12): e114028.

Whitaker KL, Winstanley K, Macleod U, Scott SE, Wardle J (2015c) Low cancer suspicion following experience of a cancer 'warning sign'. Eur J Cancer 51(16): 2473-2479.

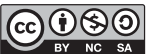

This work is licensed under the Creative Commons Attribution-Non-Commercial-Share Alike 4.0 International License. To view a copy of this license, visit http:// creativecommons.org/licenses/by-nc-sa/4.0/ 